\title{
MiR-770-5p inhibits cisplatin chemearch Paper MiR-770-5p inhibits cisplatin chemoresistance in human ovarian cancer by targeting ERCC2
}

\author{
Henan Zhao ${ }^{1}$, Xiaotang Yu ${ }^{1}$, Yanfang Ding ${ }^{1}$, Jinyao Zhao ${ }^{1}$, Guang Wang ${ }^{1}$, Xian Wu ${ }^{1}$, \\ Jiyong Jiang ${ }^{2}$, Chun Peng ${ }^{3}$, Gordon Zhuo Guo ${ }^{4}$, Shiying Cui ${ }^{1}$ \\ ${ }^{1}$ Dalian Medical University, Dalian, China \\ ${ }^{2}$ Obstetrics and Gynecology Hospital, Dalian, China \\ ${ }^{3}$ Department of Biology, York University, Toronto, Canada \\ ${ }^{4}$ Department of Radiation Oncology, Indiana University School of Medicine, Indianapolis, IN, USA \\ Correspondence to: Shiying Cui, email: scui2003@dlmedu.edu.cn, 2501532244@qq.com \\ Gordon Zhuo Guo, email: gguo1@IUhealth.org
}

Keywords: ovarian cancer, cisplatin, chemoresisitance, miR-770-5p, ERCC2

Received: January 02, 2016

Accepted: July 06, 2016

Published: July 20, 2016

\section{ABSTRACT}

In this study, we examined the role of the miRNA miR-770-5p in cisplatin chemotherapy resistance in ovarian cancer (OVC) patients. miR-770-5p expression was reduced in platinum-resistant patients. Using a 6.128-fold in expression as the cutoff value, miR-770-5p expression served as a prognostic biomarker and predicted the response to cisplatin treatment and survival among OVC patients. Overexpression of miR-770-5p in vitro reduced survival in chemoresistant cell lines after cisplatin treatment. ERCC2, a target gene of miR-770-5p that participates in the NER system, was negatively regulated by miR-770-5p. siRNA-mediated silencing of ERCC2 reversed the inhibition of apoptosis resulting from miR-770-5p downreglation in A2780S cells. A comet assay confirmed that this restoration of cisplatin chemosensitivity was due to the inhibition of DNA repair. These findings suggest that endogenous miR-770-5p may function as an anti-oncogene and promote chemosensitivity in OVC, at least in part by downregulating ERCC2. miR-770-5p may therefore be a useful biomarker for predicting chemosensitivity to cisplatin in OVC patients and improve the selection of effective, more personalized, treatment strategies.

\section{INTRODUCTION}

Ovarian cancer (OVC) is the leading cause of death due to gynecologic malignancies among women in developed countries. Epithelial ovarian cancer (EOC), which has a poor prognosis due to late diagnosis and high incidences of chemoresistance, accounts for approximately $90 \%$ of OVCs $[1,2]$. The standard treatment protocol for the initial management of OVC is cytoreductive surgery, followed by primary chemotherapy with a platinum-based regimen $[3,4]$. However, drug resistance is a major impediment to the successful treatment of OVC with chemotherapy. Chemoresistance often results in significant toxicities, such as declining bone marrow reserves, which delay the initiation of therapy with active chemo-agents and reduce quality of life [3]. Early prediction of OVC patient response to platinum-based chemotherapy and identification of the most effective agent based on primary tumor gene expression data may assist in optimizing the selection of personalized treatment regimens.

Platinum (cisplatin or carboplatin) is the firstline chemotherapeutic drug for OVC patients and a mainstay of standard treatment for advanced EOC $[5,6]$. The major effect of cisplatin treatment involves DNA binding, the production of intrastrand (or interstrand) structural crosslinks, and the formation of DNA adducts [7-10]. Nucleotide damage repair and DNA repair capacity (DRC) play critical roles in the removal of cisplatin-induced lesions, leading to altered cell growth, differentiation, apoptosis, and carcinogenesis, and thus affecting response to chemotherapy and chemoresistance $[7,11]$. 
Recent evidence indicates that microRNAs (miRNAs) play important roles in various pathways related to anticancer drug resistance, e.g., influencing the response to the conventional chemo-agents cisplatin and microtubule-targeting drugs [12-15]. However, whether and how miRNAs predict chemosensitivity and mediate drug resistance in OVC requires further investigation. In this study, we identified miRNAs that are differentially expressed in EOC patients who show complete responses (CR) or incomplete responses (IR) to primary platinum-based chemotherapy. We coupled this analysis with bio-functional experiments to determine how oncogenic-miRNA signaling pathways impact platinum-resistance. Our findings suggest that integrating miRNA expression profiles that predict platinum response, and understanding the mechanisms by which miRNAs affect chemoresistance, might improve the selection of personalized treatment plans for individual EOC patients.

\section{RESULTS}

\section{Patient characteristics}

We evaluated 86 serous EOC samples resected at the time of primary surgery from patients who subsequently received platinum-based primary therapy. All samples were collected at the Obstetrics and Gynecology Hospital, Dalian, China between July 2004 and November 2010. Fifty-two EOC patients showed a CR, and 34 showed an IR, to primary platinum-based therapy following surgery. Patient clinical characteristics are listed in Table 1.

\section{miR-770-5p is downregulated in chemotherapy- resistant EOC patients}

To identify miRNA expression signatures associated with resistance to chemotherapy in EOC patients, patient specimens were initially analyzed by miRNA microarray, the results of which were validated with qRT-PCR and qualitative in situ hybridization (ISH). Of the 768 miRNAs analyzed in the microarray, levels of 39 differed at least 2 -fold $(p<0.05)$ between CR and IR patients ( $n=7$ /group). Thirty-four (87.2\%) of these 39 miRNAs were upregulated in the CR samples, and $5(12.8 \%)$ were upregulated in the IR specimens (Figure 1A). Importantly, 2 of the 3 miRNAs with the most statistically significant differences $(p<0.0001)$ were upregulated in CR patients; the other was upregulated in IR patients. One of these three miRNAs, miR-770-5p, was upregulated 2.9-fold in the CR group versus the IR group $(p=1.66 \mathrm{E}-06$, adjusted $p$-value $=8.78 \mathrm{E}-04)$ (Figure 1A and Supplementary Table S1). To confirm this finding, we examined miR-770-5p expression using qRTPCR and ISH. As shown in Figure 1B-1C, miR-770-5p expression was lower in IR patients than in CR patients.
Target prediction was performed for miR-770-5p using three computational approaches: Ingenuity Systems (Redwood City CA, USA), MicroCosm Targets version 5 , and miRBase. As cisplatin primarily functions through binding or/and crosslinking to DNA, targets were predicted by focusing on the "DNA Replication, Recombination, and Repair" area. The top nine candidate targets related to DNA replication and repair functions are listed in Figure 1D.

\section{Prediction of chemotherapy response and survival rate in EOC patients based on miR-770- 5p expression}

We then examined the relationship between miR770-5p expression and primary chemo-responsiveness in patients in a retrospective study. A 53-sample training cohort was used to identify the miR-770-5p expression level that predicted clinical outcome. A 6.128-fold in expression served as the cutoff value for accurate prediction of response probability as determined by receiver operating characteristic (ROC) curve analysis (Figure 2A). Patient response to platinum-based therapy was accurately predicted in 43 of 53 patients for an overall accuracy of $81.1 \%$ (sensitivity, $80 \%$ and specificity, 83\%) (Figure 2B). A Mann-Whitney U test for statistical significance $(p<0.001)$ confirmed that this predictor distinguished IR patients from CR patients. The mean AUC value (area under ROC curve) was 0.849 .

To confirm the predictive value of miR-770-5p expression for primary chemosensitivity, we used miR$770-5 \mathrm{p}$ expression to predict primary chemoresistance in a separate group of patients before treatment with a platinum-based regimen. miR-770-5p expression accurately predicted primary chemotherapy response in this validation cohort (76\% accuracy; Figure 2C). Kaplan-Meier survival analysis revealed that low miR770-5p expression was associated with shorter overall survival in OVC patients compared to the high miR-770$5 \mathrm{p}$ expression group (Figure 2D-2F).

Taken together, these results indicate that miR770-5p expression level may serve as a novel predictor and prognostic biomarker of OVC patient response to platinum-based chemotherapy and survival.

\section{Overexpression of miR-770-5p inhibits survival in cisplatin-chemoresistant cell lines}

Based on the above results (Figure 1A-1C), we further confirmed the relationship between miR-770-5p expression and chemosensitivity in the human ovarian cancer cell lines OV2008 and A2780S and their cisplatinresistant variants $\mathrm{C} 13$ and $\mathrm{A} 2780 \mathrm{CP}$, respectively. As indicated in Supplementary Figure S1, miR-770-5p expression was upregulated in OV2008 and A2780S cell lines compared to the cisplatin-resistant variants. These 
Table 1: Clinicopathologic characteristics of ovarian cancer patients

\begin{tabular}{|c|c|c|}
\hline Characteristic & $\begin{array}{c}\text { Clinical Complete } \\
\text { Responders } \\
(n=52)\end{array}$ & $\begin{array}{c}\text { Clinical Incomplete } \\
\text { Responders } \\
(n=34)\end{array}$ \\
\hline Meanage,years & 50.8 & 48 \\
\hline \multicolumn{3}{|l|}{ Stage, No. of patients } \\
\hline I & 3 & 2 \\
\hline II & 8 & 7 \\
\hline III & 41 & 21 \\
\hline IV & 0 & 4 \\
\hline \multicolumn{3}{|l|}{ Grade, No. of patients } \\
\hline 1 & 3 & 2 \\
\hline 2 & 28 & 14 \\
\hline 3 & 21 & 18 \\
\hline \multicolumn{3}{|l|}{ Mean serum CA-125, m/mL } \\
\hline Before platinum & 993.2 & 1884.4 \\
\hline After platinum & 12.1 & 205.6 \\
\hline Mean survival time, months & 46 & 30 \\
\hline Mortality rate $(\%)$ & 48.3 & 70 \\
\hline
\end{tabular}

results agree with those from the clinical OVC patient specimens.

We then investigated the effects of miR-770-5p overexpression on sensitivity to cisplatin chemotherapy in the resistant cell lines after treatment with various cisplatin concentrations or following various durations of miR-770$5 \mathrm{p}$ transfection in vitro. Transfection with pre-miR-770-5p reduced $\mathrm{C} 13$ and $\mathrm{A} 2780 \mathrm{CP}$ cell viability relative to the mock and negative control groups (Figure 3A and 3B). $\mathrm{C} 13$ and $\mathrm{A} 2780 \mathrm{CP}$ cell survival was also markedly decreased after pre-miR-770-5p transfection and 24 hours of cisplatin treatment (Figure 3D).

\section{ERCC2 is a potential target of miR-770-5p}

Nucleotide excision repair (NER) has been reported to play a role in regulating both chemoresistance and apoptosis [16]. ERCC2, one of the candidate target genes involved in NER, contains a putative region (nucleotides 279-301 in the human sequence $3^{\prime}$-UTR, NM 000400.2) that matches the seed sequence of hsa-miR-770-5p (Figure 4A). To determine whether ERCC2 is a target of miR-770-5p, quantitative and qualitative analysis at both the miRNA and mRNA levels were performed in vivo and in vitro.

First, miR-770-5p and ERCC2 expression were analyzed in CR and IR patients using qRT-PCR; miR770-5p expression was negatively correlated with ERCC2 expression in both groups (Figure 4B). It is wellestablished that miRNAs suppress target gene expression primarily by inhibiting translation and/or induction of mRNA cleavage, and reciprocal expression patterns between an miRNA and the mRNA of its target gene can be detected in the same patient specimen. To confirm the miRNA-target relationship between miR-770-5p and ERCC2, miRNA and mRNA ISH was performed. Figure $4 \mathrm{C}$ shows the qualitative validation of miR-770-5p and its predicted target, ERCC2, in FFPE serial sections from same EOC patient. In the CR group, miR-770$5 \mathrm{p}$ was strongly expressed in the cancer epithelium, but ERCC2 expression was weak or undetectable in the same tumor tissues from the same patient. The same relationship between miR-770-5p and ERCC2 was also observed in IR patients. Quantitative analysis using Image-Pro 6.0 software confirmed an inverse relationship between miR770-5p and ERCC2 mRNA expression in the CR and IR groups (Figure 4D).

To determine whether ERCC2 is also modulated by miR-770-5p in vitro, the cisplatin-sensitive parental cell lines (OV2008, A2780S) and their resistant variants (C13 and $\mathrm{A} 2780 \mathrm{CP}$ ) were transfected with anti-miR-770-5p or pre-miR-770-5p, respectively. Western blotting and semiquantitative RT-PCR analyses revealed that miR-770-5p negatively regulated ERCC2 expression at both the mRNA and protein levels (Figure 4E).

\section{ERCC2 and miR-770-5p modulate sensitivity of ovarian cancer cells to cisplatin-induced apoptosis}

To determine how ERCC2 modulates chemosensitivity, we used siRNA to silence ERCC2 expression (siERCC2) in A2780S cells transfected with an miR-770-5p inhibitor. We then measured cisplatininduced apoptosis in these cells with flow cytometry and 
TUNEL assays. A2780S cells became more resistant to cisplatin after transient transfection-mediated miR-770-5p silencing (Figure 5A-5C). Furthermore, silencing ERCC2 expression in A2780S cells treated with the miR-770-5p inhibitor restored chemosensitivity to cisplatin as indicated by both flow cytometry and TUNEL assays (Figure 5).

\section{Upregulation of miR-770-5p and downregulation of ERCC2 inhibits the repair of cisplatin- induced DNA-damage in vitro}

Cisplatin and other platinum-based cancer drugs destroy tumor cells by binding to DNA strands, interfering

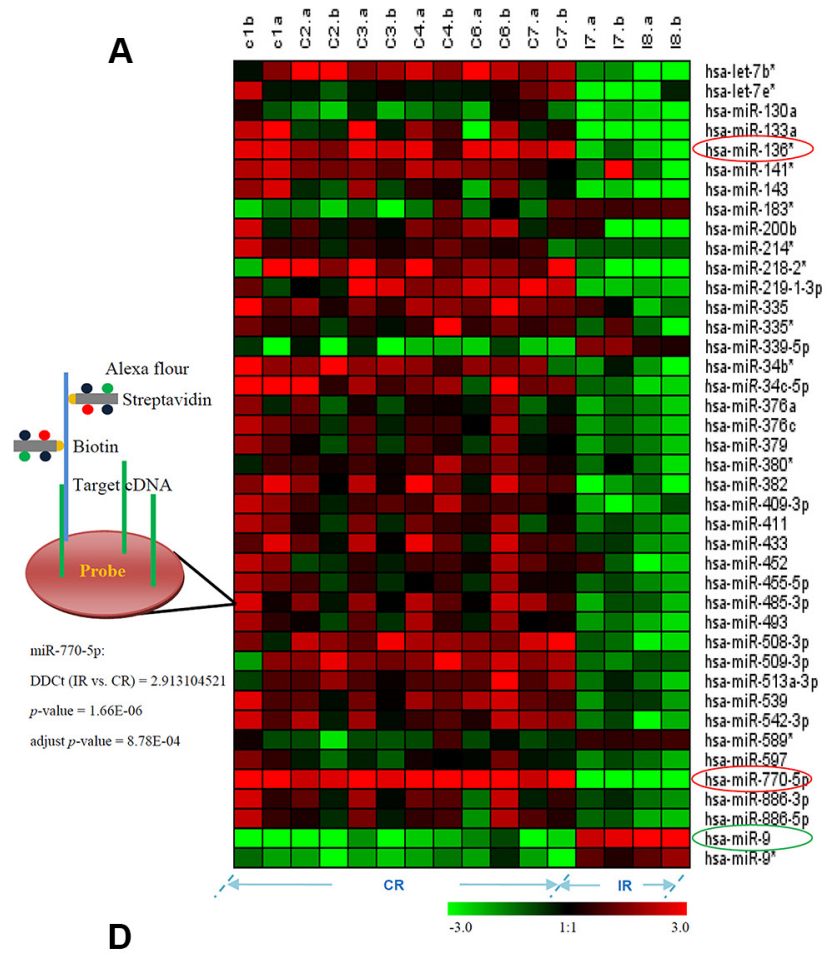

\section{B}
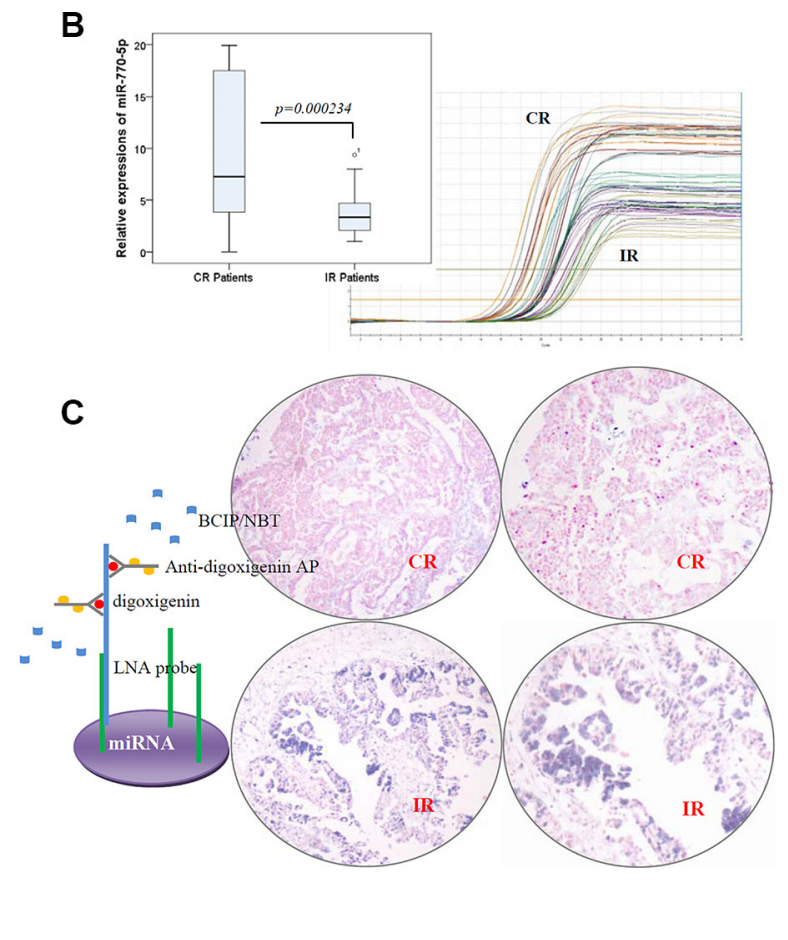

with DNA replication, and forming cisplatin-DNA adducts; chemosensitivity results from the inability to repair this DNA damage. Because the effects of miR-770$5 p$ on DNA repair might explain its ability to modulate cisplatin-resistance in ovarian cancer, we examined the role of ERCC2 in this repair process. In order to quantify the DNA damage/repair process, we measured the percentage of DNA in comet tails; tail length (in $\mu \mathrm{m}$ ), tail moment (TM), and tail olives moment (TOM) were measured in each gel (Figure 6A-6B). DNA damage was measured manually and evaluated with CASP version 1.2.3 beta2 (Figure 6C-6D). As expected, DNA damage repair-deficient A2780S cells had smaller tails than

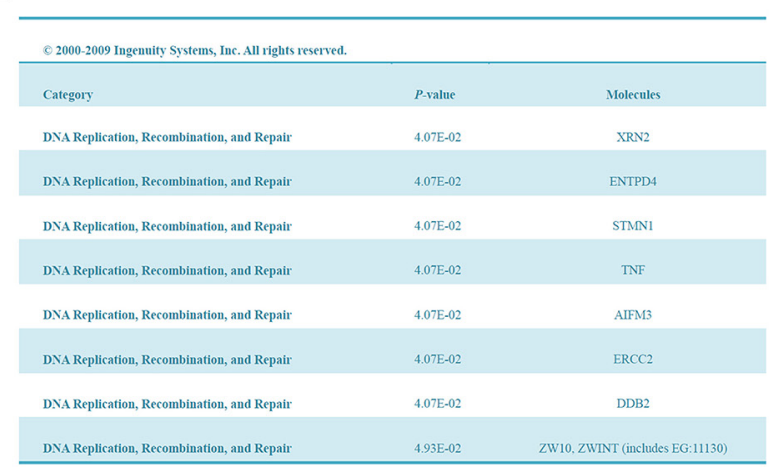

Figure 1: miR-770-5p expression is reduced in patients with chemotherapy-resistant EOC, and target predictions. (A) Hierarchical clustering of miRNA microarray analysis in complete response (CR) and incomplete response (IR) ovarian cancer patients. Two miRNAs (miR-770-5p and hsa-miR-136*, red circle) were more highly expressed $(p<0.0001)$ in the CR group, and one (hsa-miR-9, green circle) was more highly expressed in the IR group. (B) Differential miR-770-5p expression in CR and IR patients. (C) Analysis of miR-770-5p expression in CR and IR sample sets using in situ hybridization. miR-770-5p expression was higher in CR than in IR samples $(p<0.001)$. (D) miRNA target prediction and top bio-functional analysis using Ingenuity Systems software. The predicted top nine targets were related to DNA replication, recombination, and repair. 
A

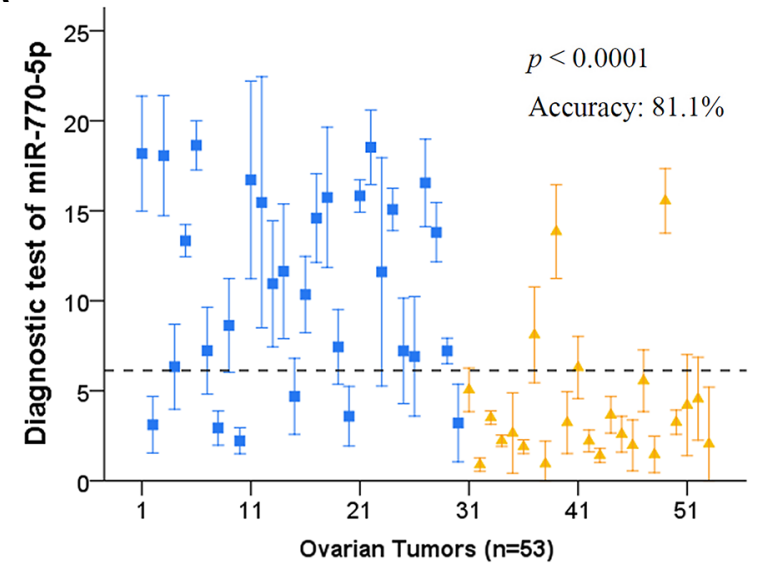

B

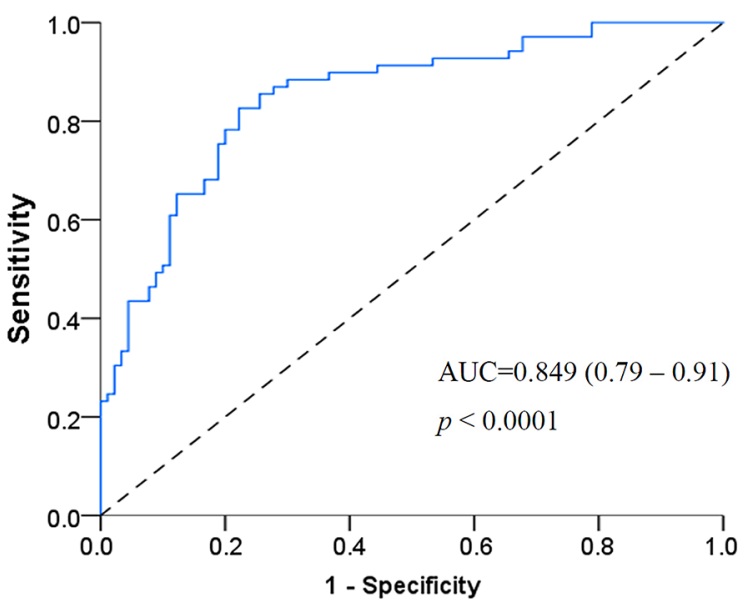

C

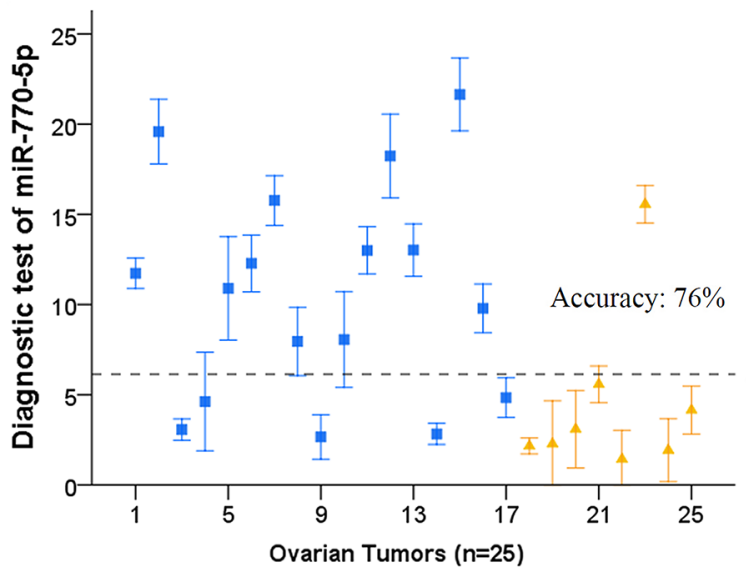

D

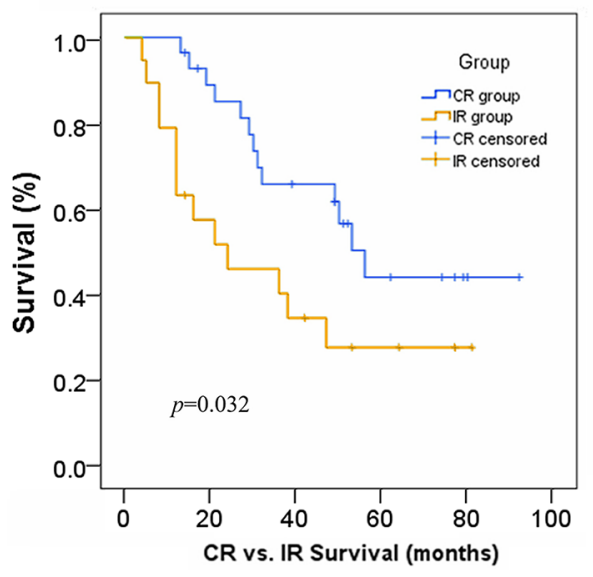

E
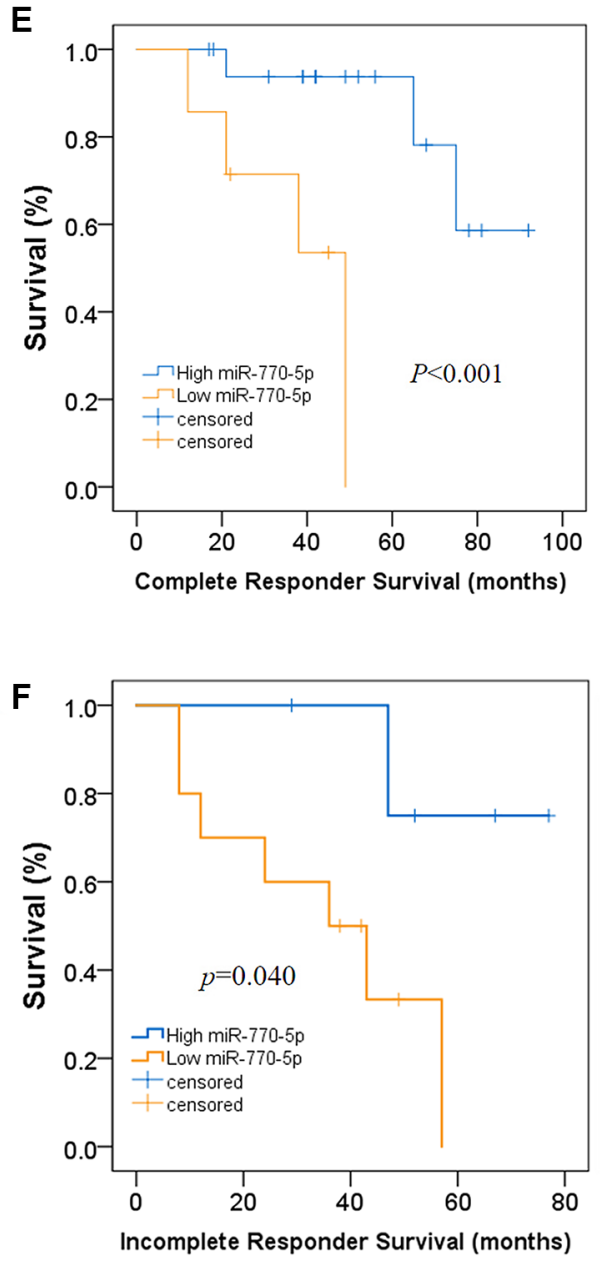

Figure 2: miR-770-5p levels predict response to platinum-based chemotherapy and survival in OVC patients. (A) Leave-one-out cross prediction of cisplatin responders (blue: CR, yellow: IR), $n=53$. a 6.128 in expression was the cutoff value having the highest Youden's index; accuracy, sensitivity, and specificity were $81.1 \%, 80 \%$, and $83 \%$ respectively. (B) Receiver operating characteristic (ROC) curve of the cisplatin responders. A Mann-Whitney $U$ test demonstrated that miR-770-5p expression distinguished IR patients from CR patients $(p<0.001)$. Mean AUC is $0.849(0.79-0.91)$. (C) Confirmation that the 6.128 cutoff predicted cisplatin response prediction as indicated by ROC curve analysis. (D) In 47 randomly selected OVC patients, overall survival was higher in those with high miR-770-5p expression ( $\mathrm{CR}=28, \mathrm{IR}=19 ; p<0.05)$. $(\mathbf{E}-\mathbf{F})$. Overall survival of $\mathrm{CR}$ and IR patients divided into high and low miR-770-5p subgroups. Kaplan-Meier survival analysis also indicated that low miR-770-5p expression was associated with shorter overall survival compared to the high expression group ( $n=25$ for CR and $n=15$ for IR, $p<0.001$ for CR group, $p<0.05$ for IR group). AUC: area under the curve. 

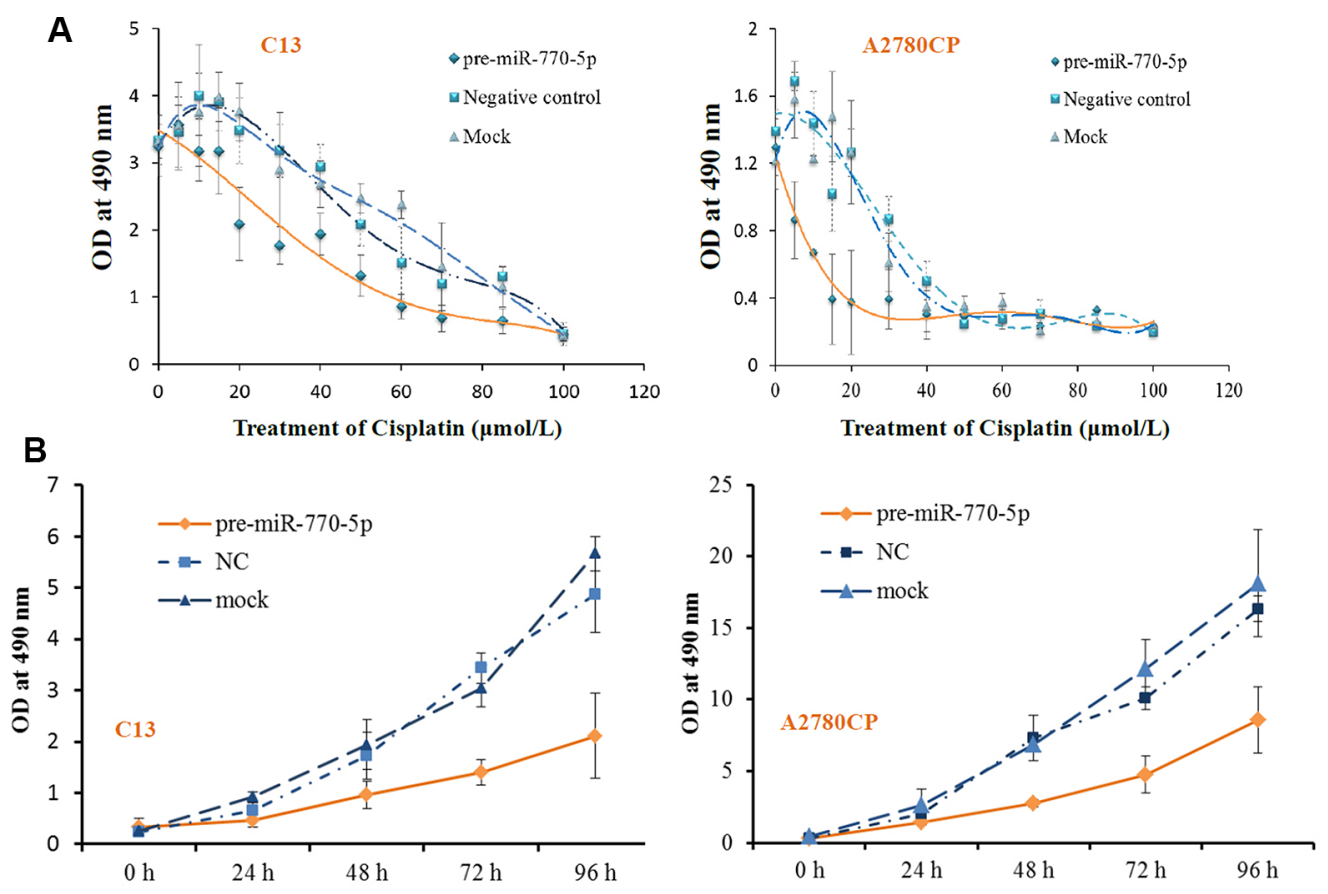

C
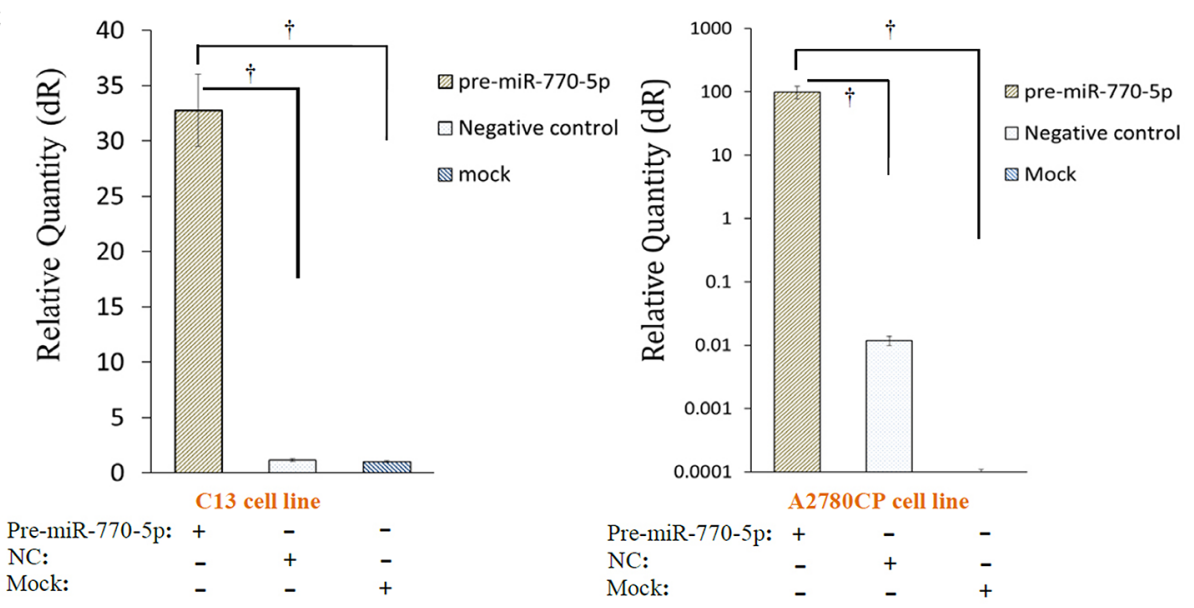

D

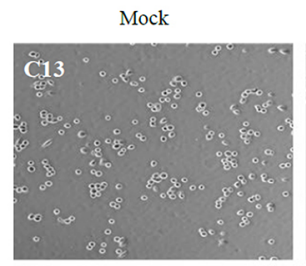

Negative control

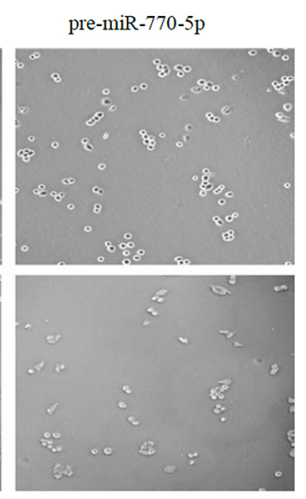

Figure 3: Overexpression of miR-770-5p inhibits survival of chemo-resistant cell lines after cisplatin treatment. (A) Transfection with pre-miR-770-5p inhibited survival in C13 and A2780CP cells treated with various concentrations of cisplatin compared to mock and negative control groups ( $n=10$ for all groups). (B) Viability decreased in $\mathrm{C} 13$ and A2780CP cells after different lengths ( 0 to $96 \mathrm{~h}$ ) of miR-770-5p transfection compared to mock and negative control groups (C) Real-time RT-PCR confirmed the success of pre-miR770-5p transfection. (D) Pre-miR-770-5p, negative control, and mock transfected cell lines (C13 and A2780CP) were cultured in media containing cisplatin. Cell numbers were counted after 48 hours of treatment. ${ }^{\dagger}$, statistically significant difference in miR-770-5p expression compared to either negative control or mock-transfected cells (all $p<0.01$ ). 
A2780CP cells. After transfection with the miR-770-5p inhibitor, A2780S DNA repair abilities increased, suggesting that these cells became more resistant to cisplatin. However, siRNA-mediated ERCC2 silencing reversed this increase. In addition, silencing ERCC2 inhibited DNA damage repair similarly to miR-770-5p upregulation in A2780CP cells (Figure 6). A representative image of the modified COMET assay used for data analysis is shown in Figure 5B. These results indicate that the effect of miR-770-5p on cisplatin-sensitivity was at least partly mediated by ERCC2.

\section{DISCUSSION}

Platinum-based chemotherapy is the standard firstline treatment for advanced-stage EOC, and cisplatin is the drug used most often after primary surgery [3]. However, about $30-40 \%$ of patients who receive platinum-based chemotherapy experience disease progression or rapidly develop resistance to this non-targeted therapy [3, 17]. Therefore, early identification of platinum sensitivity would benefit platinum-resistant EOC patients, for whom other first-line therapies could be used [3, 17,18-22].

Using miRNA microarrays, qRT-PCR, and ISH, we demonstrated that some miRNAs are differentially expressed in EOC patients who show CRs or IRs to primary chemotherapy. Preliminary experiments and comprehensive computational analysis identified miR$770-5 p$ as a particularly relevant miRNA. miR-770-5p was downregulated in chemoresistant EOC patients, indicating that miRNAs are involved in the response to platinumbased regimens. To determine the impact of miR-770$5 p$ on chemoresistance, we performed retrospective and prospective assessments of miR-770-5p as a predictor

\section{A} miRNA 770-5p: 3'- a C C G G GAC $\boldsymbol{U} \in \boldsymbol{U} G C \boldsymbol{A} C \subset \boldsymbol{A} \boldsymbol{U} \in \boldsymbol{A} \subset \mathrm{C} u-5^{\prime}$ ||$|:|$ |: | | | |:|||| ERCC2, H. sapiens UTR 279-301: 5'-g G GC T $\subset \boldsymbol{A} G \mathrm{G} \boldsymbol{T} \mathrm{C} C \boldsymbol{T} \mathrm{G} G \mathrm{G} \mathrm{T} \mathrm{G} \boldsymbol{T} \mathrm{G} \mathrm{GC}-3^{\prime}$ B
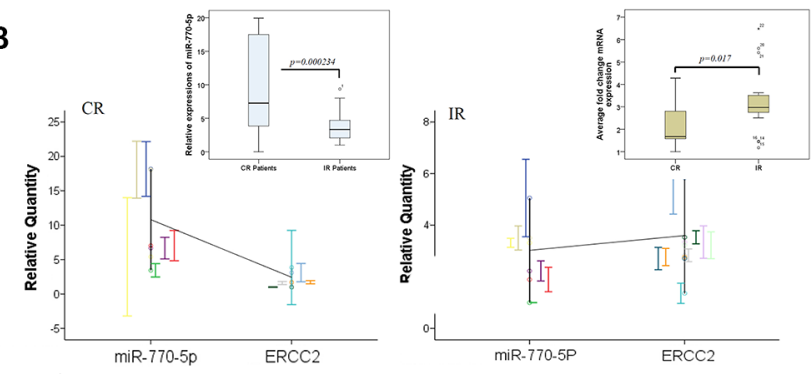

c
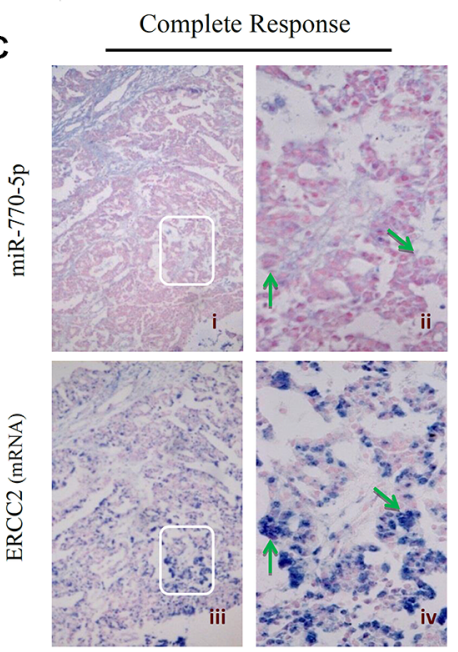

Incomplete Response

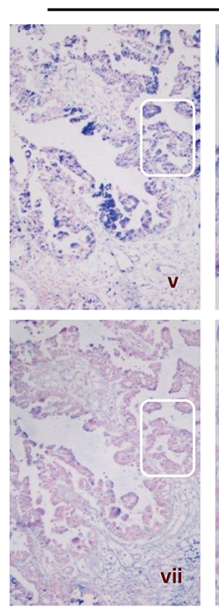

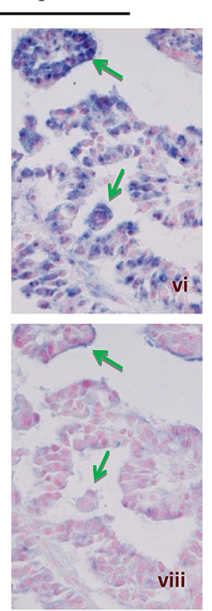
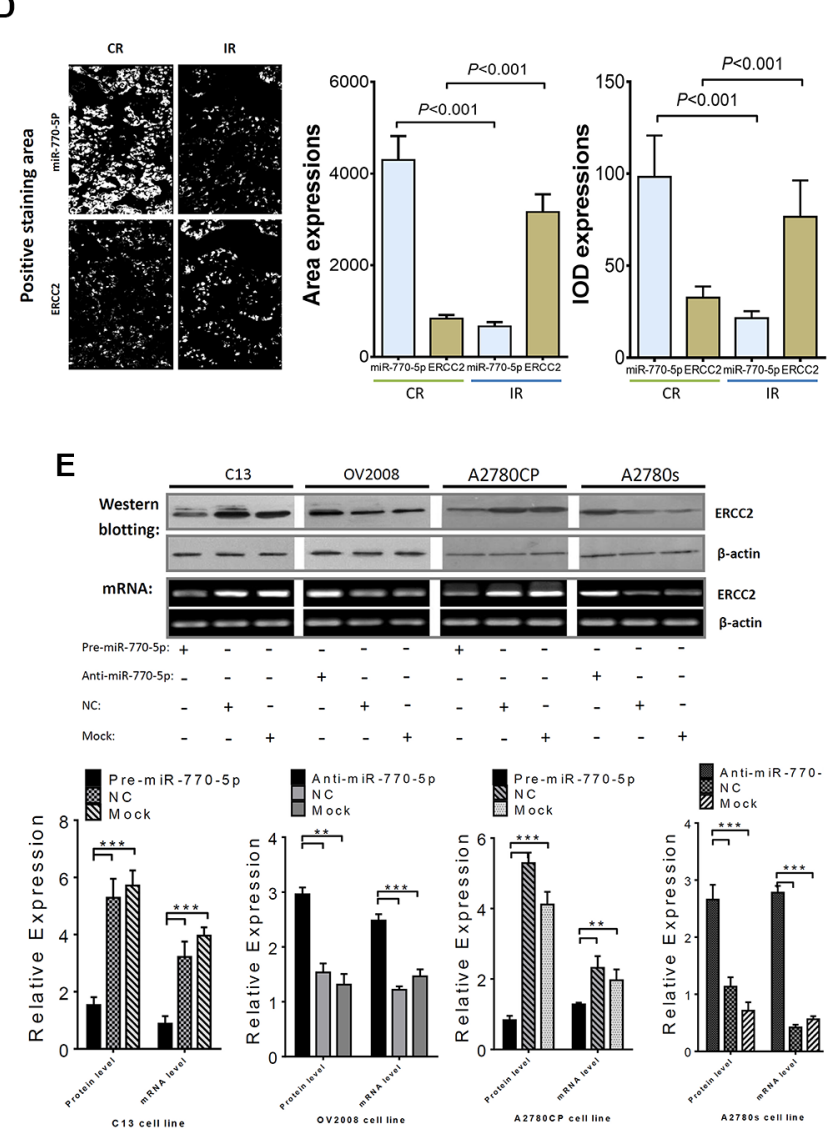

Figure 4: miR-770-5p inhibits ERCC2 in vivo and in vitro. (A) Sequence alignment of human miR-770-5p with the 3'-UTR of ERCC2. (B) Differences in miR-770-5p (left panel) and ERCC2 (right panel) expression between the CR and IR groups. (C) Qualitative and quantitative examination of miR-770-5p and ERCC2 expression by ISH in FFPE sections from EOC patients. hsa-miR-770-5p was highly expressed in the tumor epithelium (green arrows in ii) of CR patients (i-iv), and ERCC2 expression was absent in the same tumor area (in iv). In contrast, IR tumors (v-viii) expressed low levels of hsa-miR-770-5p, but higher levels of ERCC2 (green arrows in viii). The areas in white boxes are shown enlarged on the right. (D) Quantitative analysis of miR-770-5p (miRNA) and ERCC2 (mRNA) expression in tumors conducted with Image-Pro 6.0 (positive areas: white color; IOD: integrated optical density) (E) Overexpression of miR-770-5p downregulates ERCC2 protein and mRNA levels in C13/A2780CP cells, and anti-miR-770-5p-treatment reversed this effect in OV2008/ A2780S cells (all $p<0.05)$. 

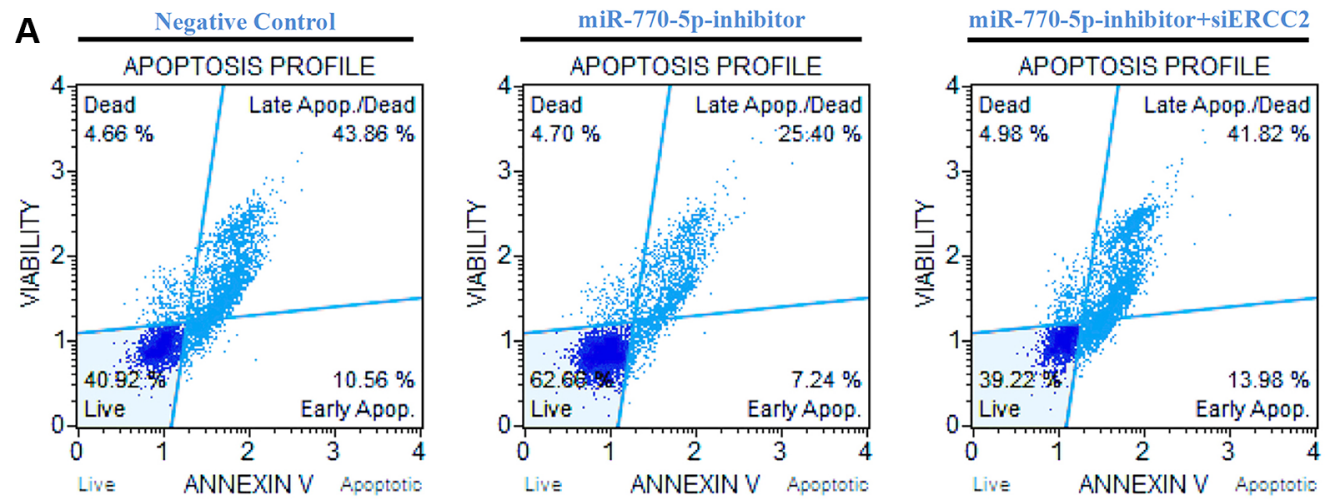

B Negative control
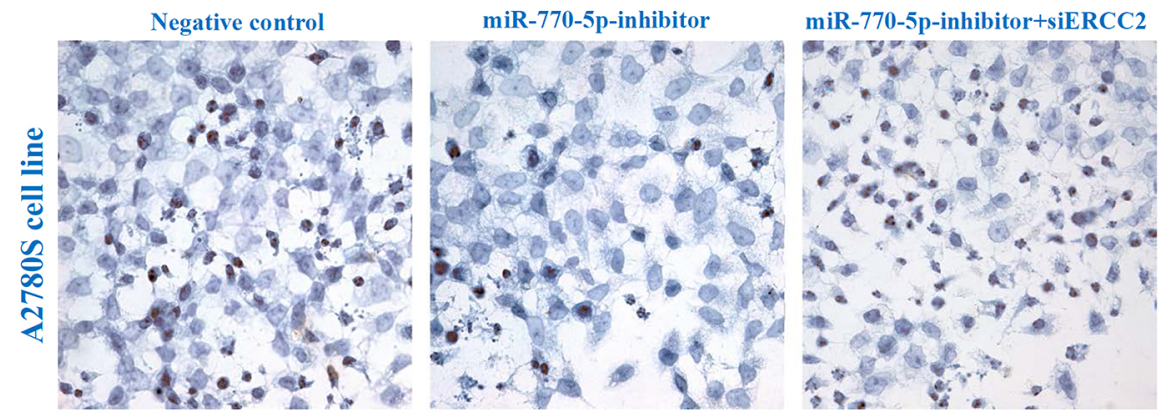

C
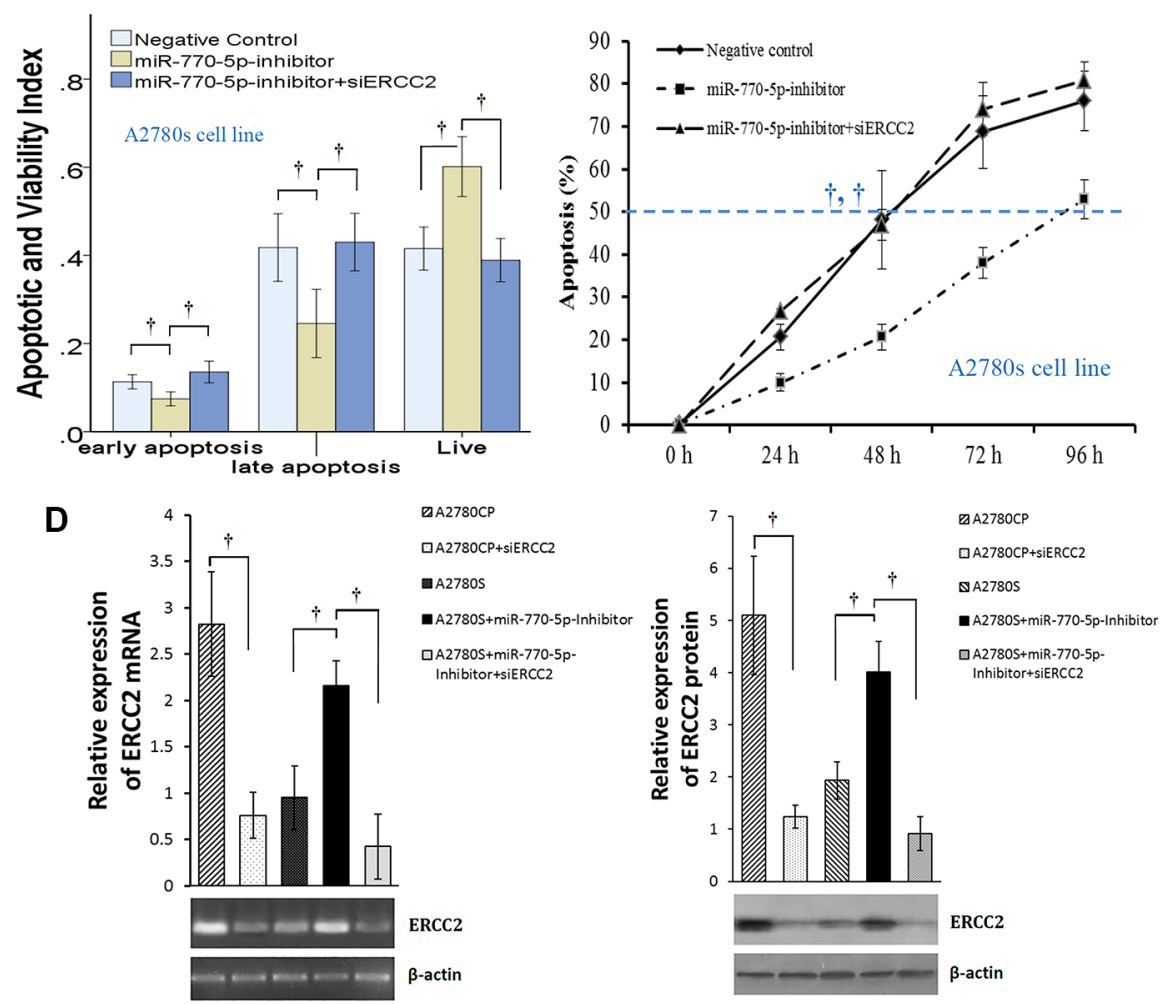

Figure 5: Effects of ERCC2 on miR-770-5p-modulated chemoresistance in ovarian cancer cells. (A) Flow cytometric detection of apoptosis via Annexin V-FITC/PI staining in cisplatin-sensitive A2780S cells after treatment with cisplatin $(20 \mu \mathrm{M})$ for $48 \mathrm{~h}$ after transfection with miR-770-5p inhibitor, negative control, or miR-770-5p inhibitor + siERCC2. (B) After transfection with miR770-5p inhibitor, A2780S cells were treated with cisplatin $(40 \mu \mathrm{M})$ for $24 \mathrm{~h}$. TUNEL staining indicated that apoptosis decreased after cisplatin treatment in A2780S cells transfected with miR-770-5p inhibitor; siRNA-mediated ERCC2 silencing reversed this effect. Original magnification: 400x. (C) Analysis of flow cytometry results (left, $n=10 /$ group) and TUNEL staining (right, $n=6 /$ group). Statistical analyses of percent values and time to 50\% apoptosis were conducted using Pearson's $\chi^{2}$ test and ANOVA, respectively. (D) RT-PCR and western blot analysis confirmed that siRNA inhibited the expression of ERCC2 mRNA and protein in A2780 cell lines. ${ }^{\dagger} p<0.001$. 

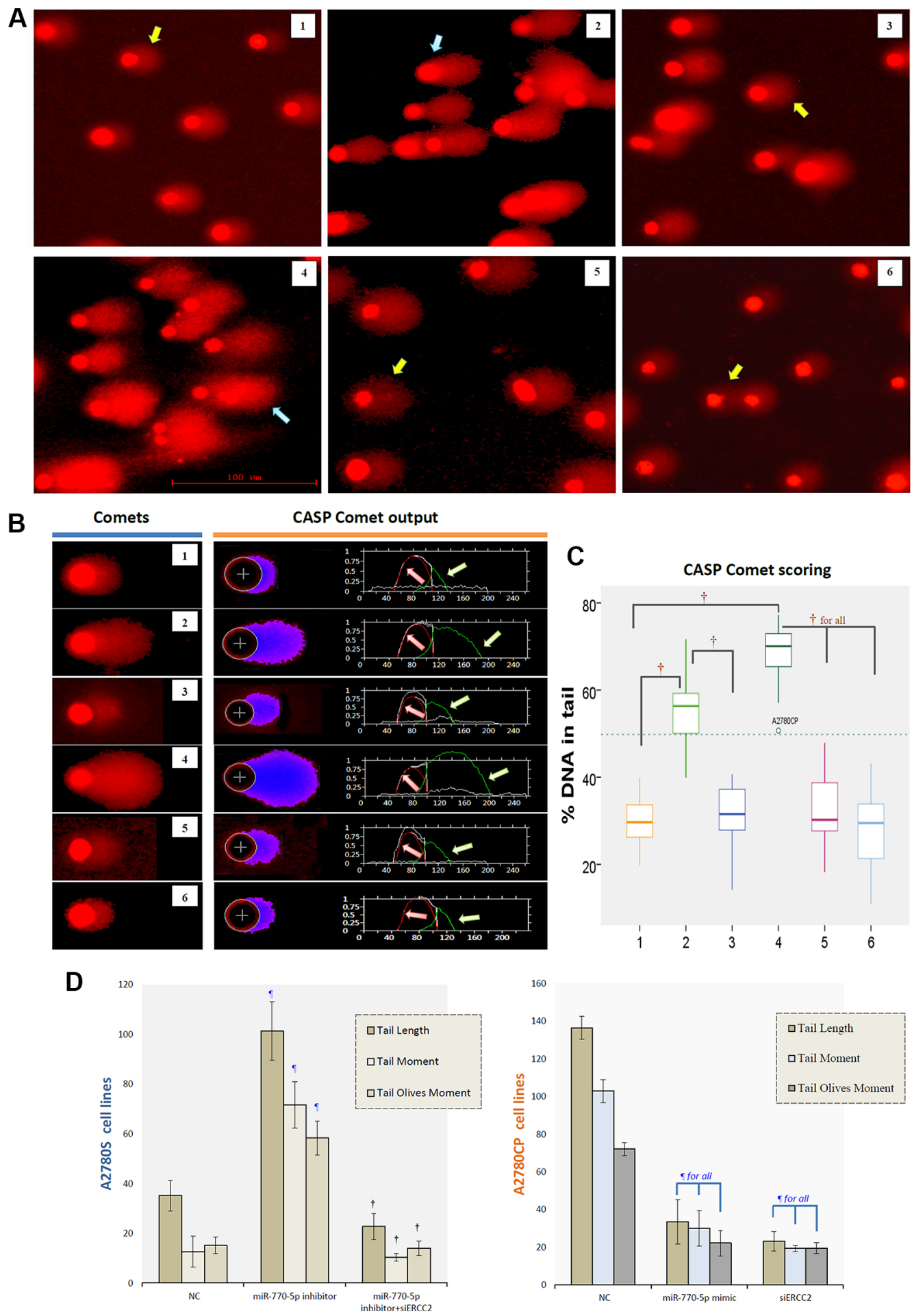

Figure 6: CASP comet analysis of alkaline comet assay images. (A) Representative image of the modified COMET assay used to evaluate DNA damage after treatment with cisplatin. The blue arrow indicates a comet with a long tail, and yellow arrow a comet with a short tail. The scale bar is $100 \mu \mathrm{m}$. (B) Alkaline comet assay images for each group after cisplatin treatment are shown on the left, and CASP comet output and analysis are shown on the right. Red lines (indicated by red arrows) represent the head of comet, and green lines (indicated by green arrows) represent the tail of comet. (C) Amounts of DNA damage with and without cisplatin treatment in each group. ${ }^{\dagger} p<0.001$. 1: A2780S NC, 2: A2780S miR-770-5p inhibitor, 3: A2780S miR-770-5p inhibitor + siERCC2, 4: A2780CP NC, 5: A2780CP miR-770-5p mimics, 6: A2780CP siERCC2. (D) Spontaneous and cisplatin-induced means \pm S.D. for three additional replicates of the Comet assay after cisplatin treatment. " $p<0.001$ compared to negative controls of the same cell type; ${ }^{\dagger} p<0.001$ compared to the scrambled miR-770-5p or mimics group of the same cell type. 
of primary chemosensitivity before and after patients received a platinum-based regimen. Unexpectedly, high miR-770-5p expression predicted chemoresistance with an accuracy of up to $81.1 \%$ in the retrospective and $76 \%$ in prospective assessments, with a 6.128-fold in expression serving as the cutoff value. This finding demonstrates that miR-770-5p expression immediately after primary EOC diagnosis can be used as a biomarker to assist in selecting the appropriate chemotherapy regimen before treatment begins, helping to avoid unnecessary toxicities and enhance quality of life. To confirm the association between miR-770-5p and chemo-resistance in vitro, we transiently transfected OVC cell lines with an miR-770-5p expression vector. Ectopic miR-770-5p expression increased survival and reduced apoptosis in ovarian cancer cells, suggesting that miR-770-5p also modulates therapeutic response.

To understand the mechanism by which miR-770-5p regulates chemoresistance in $\mathrm{OVC}$, we identified possible target genes using computational approaches. One of the candidate targets was ERCC2, a gene in the NER system that is involved in DNA replication, recombination, and repair [7, 23-25]. Cisplatin activity is mediated through the formation of cisplatin-DNA adducts [26]. The NER system removes these adducts, which can lead to chemoresistance, and DRC thus plays a critical role in the response to chemotherapy and chemo-resistance [7, 11]; reduced DRC may increase the response to chemotherapies that damage cancer cell DNA. Here, we detected an inverse correlation between miR-770-5p and ERCC2 expression both in tumor specimens from OVC patients who received platinum-based chemotherapy and in vitro.

To determine how ERCC2 and miR-770-5p act together to modulate cisplatin-resistance, we used siRNAs to silence ERCC2 expression (siERCC2) in A2780S cells transfected with an miR-770-5p inhibitor. siRNAmediated silencing of ERCC2 reversed the inhibition of apoptosis that resulted from miR-770-5p downregulation in A2780S cells. To investigate the mechanism underlying this effect, the comet assay, a sensitive and reliable method for studying DNA damage induced by platinum and other chemical agents, was used to assess DNA damage and DRC [27]. The results confirmed that the inhibition of apoptosis was due to increased DRC. Together, these findings suggest that miR-770-5p might directly target ERCC2, the downregulation of which increases cisplatin chemosensitivity in OVC. Thus, the anti-oncogenic and cisplatin chemosensitivity-enhancing effects of miR-770$5 \mathrm{p}$ in OVC might depend on its ability to downregulate ERCC2 expression (Figure 7).

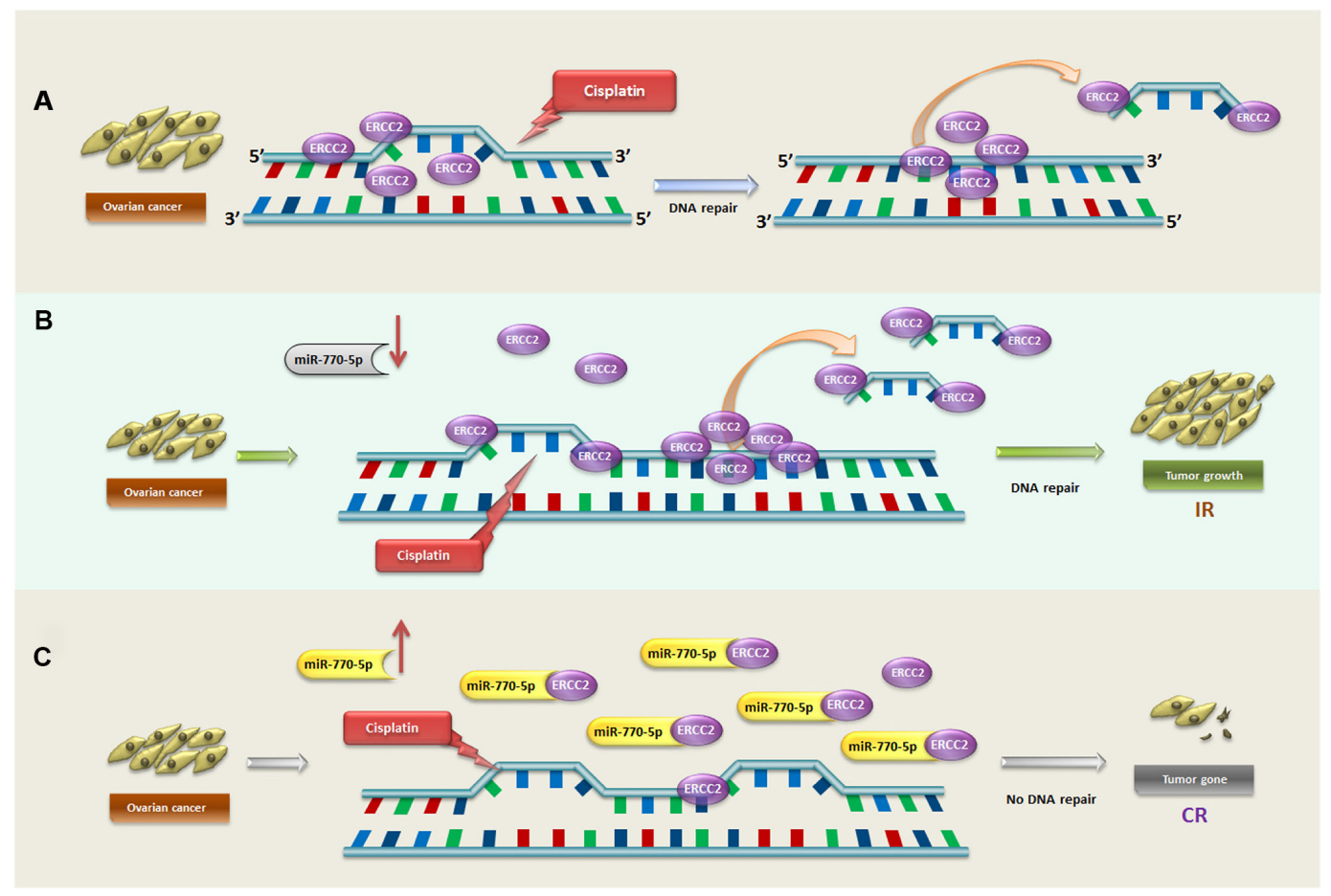

Figure 7: Schematic model depicting mediation of response to cisplatin-based primary chemotherapy by miR-770-5p and ERCC2 OVC patients. (A) The general mechanism of ERCC2-dependent DNA damage repair after cisplatin treatment in OVC patients. After the DNA intra-strand is unwound and damaged by cisplatin, ERCC2 recognizes and repairs the DNA adducts. In OVC patients with IR to cisplatin, miR-770-5p is downregulated and does not suppress ERCC2 expression; ERCC2 is thus overexpressed in OVC cells and activates excision repair of DNA damaged by cisplatin, ultimately accelerating tumor cell growth (B) Conversely, in OVC patients with CR to cisplatin, miR-770-5p is upregulated and strongly suppresses ERCC2 expression in tumor cells; this reduces ERCC2induced DNA damage repair, allowing cisplatin to damage DNA and ultimately activating tumor cell apoptosis $(\mathbf{C})$ ERCC2 = excision repair cross-complementing rodent repair deficiency, group 2; IR = incomplete response; $\mathrm{CR}=$ complete response. 
Pharmacokinetic analyses of miRNAs are an innovative method for predicting treatment response and chemoresistance $[12,28]$. In this study, we report that miR-770-5p enhances chemosensitivity at least in part by targeting ERCC2. Therefore, the miR-770-5p-ERCC2 interaction might be a useful biomarker for predicting chemosensitivity to cisplatin in OVC patients. Future examinations of miRNA expression profiles coupled with the expression of valid targets might improve predictions of sensitivity to primary chemotherapy and assist in the development of effective individualized cancer treatments.

\section{MATERIALS AND METHODS}

\section{Patient samples and cell lines}

We evaluated a total of 86 serous EOC samples resected at the time of primary surgery from patients who went on to receive platinum-based chemotherapy. The clinicopathologic characteristics of these patients are listed in Table 1. All tissue samples were collected at the Obstetrics and Gynecology Hospital, Dalian, China between July 2004 and November 2010. Two independent pathologists with no knowledge of the patients' clinical data reviewed the pathological specimens before they were formalin fixed and paraffin embedded (FFPE). Cases were classified according to the International Federation of Gynecology and Obstetrics (FIGO) staging system. Therapeutic response was evaluated as previously reported [29]. Medical records were examined by a single gynecologic oncologist and scored using standard criteria for patients with measurable disease based on WHO guidelines [29, 30]. A complete response (CR) was classified as a complete disappearance of all measurable and assessable disease or, in the absence of measurable lesions, by CA-125 levels $<30 \mathrm{U} / \mathrm{mL}$ measured by RIA or ELISA six months after treatment with platinum-based drugs. CA-125 response criteria were based on established guidelines [29, 31, 32]. Patients who exhibited only a partial response, had no response, or progressed during primary therapy were classified as having an incomplete response (IR). Fifty-two OVC patients showed a CR and 34 showed an IR after primary platinum-based therapy following the surgery. FFPE blocks were obtained after surgery.

In vitro experiments were performed with two different pairs of human OVC cell lines; each pair included one cisplatin-sensitive parental cell line (A2780S and OV2008) and its cisplatin-resistant variant (A2780CP and $\mathrm{C} 13$, respectively) $[33,34]$.

\section{Cell culture, transfection and treatment}

Ovarian cancer cells were cultured in RPMI-1640 medium (Invitrogen, Burlington, ON) supplemented with $10 \%$ fetal bovine serum and maintained at $37^{\circ} \mathrm{C}$ with $5 \% \mathrm{CO}_{2}$ as reported previously $[33,34]$. All tissue culture reagents were obtained from Sigma-Aldrich (St. Louis, MO, USA). The miR-770-5p mimics and inhibitors were designed and chemically synthesized by Ambion (Cat\#38422-01; Life Technologies Corporation, Denmark).

Lipofectamine 2000 (Invitrogen) was incubated with pre-miR-770-5p (miRNA mimic), anti-miR-770$5 \mathrm{p}$ (inhibitor), or scrambled negative controls (Ambion, mock) at a concentration of $90 \mathrm{nM}$ and incubated in serum-free 1640 for $20 \mathrm{~min}$ before being added to cancer cells. Cells were incubated at $37^{\circ} \mathrm{C}$ for $4 \mathrm{~h}$ and then transferred to $10 \%$ FBS. Protein and RNA were harvested $48 \mathrm{~h}$ after transfection. For cisplatin treatment, cells were maintained in medium with the desired doses of cisplatin (Cat\# P4394; Sigma, USA).

\section{miRNA microarray and data analysis}

A microarray platform optimized for the analysis of a panel of 768 human miRNAs was used to analyze and compare miRNA expression patterns between EOC patients who showed a CR $(n=7)$ or an IR $(n=7)$ to platinum-based chemotherapy. Total RNA enriched for miRNAs was extracted from FFPE tissues using the Ambion mirVana microRNA isolation kit (Cat\#AM1975; Ambion, USA). The quality of total RNA was assessed using an Agilent Bioanalyzer (Agilent Technologies, Santa Clara CA). Individual real-time quantitative polymerase chain reaction assays were performed in a TaqMan low-density array (TLDA; Applied Biosystems) by the Shannon McCormack Advanced Molecular Diagnostics Laboratory Research Services, Dana Farber Cancer Institute, Harvard Clinic and Translational Science Center. The normalized microarray data were analyzed using Statminer version 3.0 (Integromics ${ }^{\mathrm{TM}}$ ) software.

\section{miRNA target prediction and pathway analysis}

miRNAs target prediction was conducted using three computational approaches: Ingenuity Systems (Redwood City CA, USA), MicroCosm Targets version 5 (http://www.ebi.ac.uk/enright-srv/microcosm/htdocs/ targets/v5/), and miRBase (http://www.mirbase.org/). The target prediction algorithm used here is estimated to have a $20-30 \%$ false-positive rate. This level of false discovery is unlikely to affect the overall network findings, despite the large number of top predicted gene targets. Functional analysis of these predicted targets was performed to identify relevant biological pathways according to significant gene expression. To incorporate information from previous research on the identified miRNAs, the target networks of the relevant biological pathways, especially those related to cancer development, were predicted using commercially available software (Ingenuity Systems, Redwood City CA). 


\section{Quantitative real-time PCR}

Quantitative Real-Time PCR (qRT-PCR) was performed using the TaqMan MicroRNA Reverse Transcription Kit (Applied Biosystems, Foster City CA, USA) on an Agilent Technologies Stratagent Mx3000P (USA). A $500 \mathrm{ng}$ mass of total RNA in $1 \mu \mathrm{L}$ of RNase-free water was used in $20 \mu \mathrm{L}$ of RT mix. The following primer pairs were used: has-miR-770-5p (ABI miRNA specific primers, ABI\#002002), ERCC2 sense: 5'-CATGGCATACCAGAGAGCATATCC- ${ }^{\prime}$ ' and antisense: 5'-AGTTGAGCAACTTTCGAAGCTCTTC-3' (GenePharma Co., Ld, ShangHai, China). The products were detected with SYBR Green I, and relative miRNA or mRNA levels were calculated using the comparative $\mathrm{Ct}$ (cycle threshold, 2-DDCt) method with U6 and GAPDH as the endogenous controls, respectively. Samples from at least three independent experiments, each measured in duplicate, were analyzed, and the data are expressed as the mean $\pm \mathrm{SD}$.

\section{MTS cell viability assay}

Cell survival was determined using the CellTiter $96{ }^{\circledR}$ AQueous Non-Radioactive Cell Proliferation Assay kit (Cat\#P9625; Promega Co., USA). Briefly, cells were cultured in 96-well plates at a density of $1 \times 10^{3} /$ well for $48 \mathrm{~h}$ after transfection, and then treated with $0,5,10,15$, $20,30,40,50,60,70,85$ or $100 \mu \mathrm{M}$ cisplatin for $48 \mathrm{~h}$. MTS/PMS solution composed of $20 \mu \mathrm{L}$ each of a novel tetrazolium compound [3-(4,5-dimethylthiazol-2-yl)5-(3-carboxymethoxyphenyl)-2-(4-sulfophenyl)-2Htetrazolium, inner salt; MTS] and an electron coupling reagent (phenazine methosulfate; PMS) was added to one 96-well plate for a total volume of $100 \mu \mathrm{L}$ with cultured cells followed by incubation at $37^{\circ} \mathrm{C}$ in a humidified, $5 \%$ $\mathrm{CO}_{2}$ atmosphere for $1 \mathrm{~h}$. The absorbance at $490 \mathrm{~nm}$ was measured using an ELISA plate reader (PowerWavex 340, Bio-Tek Instruments Inc., Winooski, VT, USA). Each point represents the mean \pm S.D. of triplicates. Responses to drug treatment were assessed by standardizing treatment groups to untreated controls.

\section{Cellular apoptosis assay with flow cytometry and TUNEL}

Annexin $\mathrm{V}$ binding with propidium iodide (PI) staining was performed using the Muse ${ }^{\mathrm{TM}}$ Annexin V et Dead Cell kit (Merck KGaA, Darmstadt, Germany). Ovarian cancer cells were seeded at $1 \times 10^{5}$ cells $/ \mathrm{mL}$ in 6-well plates and incubated at $37^{\circ} \mathrm{C}$ in a humidified atmosphere with $5 \% \mathrm{CO}_{2}$ for $48 \mathrm{~h}$ after transfection. $\mathrm{C} 13$ cells were then treated with $30 \mu \mathrm{M}$, OV2008 cells with $20 \mu \mathrm{M}$, and A2780CP and A2780S cells with $15 \mu \mathrm{M}$ cisplatin for 48 hours, after which cells were dissociated using $0.05 \%$ EDTA-free trypsin and washed with cold
PBS. Approximately $1 \times 10^{6}$ cells were suspended in $100 \mu \mathrm{L}$ of Annexin V incubation reagent. After incubation in the dark for 20 minutes at room temperature, cellular fluorescence was analyzed with a Muse ${ }^{\mathrm{TM}}$ Cell Analyzer (EMD Millipore Co., Germany) within 30 minutes. Control tubes containing binding buffer only and cells treated with Annexin V alone or PI alone were initially used to calibrate the instrument. The nuclear morphology of apoptotic cells was determined at the same time using the Showed TUNEL in situ apoptosis detection kit (KeyGene Biotech Inc., China) following the manufacturer's instructions. Apoptotic cells (brown staining) were counted under a microscope.

\section{miRNA and RNA in situ hybridization (ISH)}

All reagents were maintained in an RNase-free environment to minimize RNase contamination. ISH was performed on patient FFPE sections according to previously described protocols [33]. The probes used for ISH were hsa-miR-770-5p (Exiqon; Cat\#38422-01) and human ERCC2 (an EcoRI-BamH1 fragment with antisense and sense digoxigenin-labeled riboprobes which were in vitro-transcribed from the full-length human ERCC2 coding sequence according to the Boehringer-MannheimRoche protocol). After removing the liquid mounting medium (LMM, Cat\#19477; Aqueous Mounting Media, Quick-Mount 4801 Daido Sangyo Co. LDT, Tokyo Japan), the transferred sections were treated with proteinase $\mathrm{K}$ (30 $\mu \mathrm{g} / \mathrm{mL}$, Amresco; Cat No: 1227B016) for $5 \mathrm{~min}$, followed by three washes in PBS. The sections were incubated with pre-hybridization buffer $(10 \mathrm{~mL}$ formamide, $5 \mathrm{~mL} \mathrm{20 \times}$ SSC, $2 \mathrm{~mL} 50 \times$ Denhardt's, $250 \mu \mathrm{L} 20 \mathrm{mg} / \mathrm{mL}$ yeast RNA, $1000 \mu \mathrm{L} 10 \mathrm{mg} / \mathrm{mL}$ salmon sperm DNA, $0.4 \mathrm{~g}$ blocking powder, and $1.75 \mathrm{~mL}$ DEPC-treated water) at $55^{\circ} \mathrm{C}$ for $1 \mathrm{~h}$. Hybridization buffer containing the probes for hasmiR-770-5p or ERCC2 was applied to each section and hybridized overnight at $55^{\circ} \mathrm{C}$. On the second day, after washing with $2 \times \mathrm{SCC}$, the sections were incubated with anti-DIG-Fab-AP (Roche; Cat\#11376621) for $2 \mathrm{~h}$ at room temperature. After washing, the sections were stained with BCIP $(3.5 \mu \mathrm{L} / \mathrm{mL}) / \mathrm{NBT}(4.5 \mu \mathrm{L} / \mathrm{mL})$ solution (Amresco; Cat\# 0885/0329) in a humidified chamber at room temperature in the dark overnight. Then, the sections were counterstained with nuclear fast red. After dehydration in ascending concentrations of ethanol and clearing in xylene, the sections were mounted in mounting medium. Positive controls and no-probe controls were included for each hybridization procedure.

\section{Reverse transcription PCR}

Total RNA was prepared using Trizol reagent following manufacturer's instructions. Reverse transcription-polymerase chain reaction (RT-PCR) was conducted as previously described [34, 35]. Newly 
synthesized cDNA was amplified by PCR. The $20 \mu \mathrm{L}$ reaction mixture contained $10 \mu \mathrm{L}$ of cDNA template, $5 \times 5 \mu \mathrm{L}$ PCR Buffer, $0.25 \mu \mathrm{L}$ of Taq polymerase, and $0.5 \mu \mathrm{L}$ of primer mixtures. The following primers were used: for ERCC2 expression, sense: 5'-CATGGCATACCAGAGAGCATATCC-3' and antisense: 5'- AGTTGAGCAACTTTCGAAGCTCTTC-3' (product size, $110 \mathrm{bp}$ ); for GAPDH (housekeeping gene) expression, sense: 5'-CATGAGAAGTATGACAACAGCCT-3' and antisense: 5'-AGTCCTTCCACGATACCAAAGT-3' (product size, $113 \mathrm{bp}$ ). The RT-PCR cycle was as follows: RT at $42^{\circ} \mathrm{C}$ for $45 \mathrm{~min}, 85^{\circ} \mathrm{C}$ for $5 \mathrm{~min}$; PCR at $94^{\circ} \mathrm{C}$ for $30 \mathrm{~s}, 60^{\circ} \mathrm{C}$ for $30 \mathrm{~s}$, and $72^{\circ} \mathrm{C}$ for $1 \mathrm{~min}$, followed by 40 cycles of amplification. PCR products were analyzed with $1.5 \%$ agarose gel electrophoresis in the presence of ethidium bromide for UV light transilluminator visualization.

\section{Western blot analysis}

Harvested cells were lysed in lysis buffer (Beyotime Institute of Biotechnology, Shanghai, CN), and lysates were evaluated for protein concentration using the BCA method (Beyotime Institute of Biotechnology, Shanghai, $\mathrm{CN})$. Proteins $(20 \mu \mathrm{g})$ were separated on $10 \%$ SDSPAGE gels and transferred to nitrocellulose membranes. Membranes were blocked in PBS containing 0.05\% Tween 20 (TBST)-5\% nonfat milk and incubated with primary antibody (rabbit anti-ERCC2, 1:500 and rabbit anti- $\beta$ actin, 1:1000; ProteinTech) in PBST-5\% nonfat milk overnight at $4^{\circ} \mathrm{C}$. After secondary antibody incubation, membranes were visualized with BeyoECL Plus A/B detection kit (Beyotime Institute of Biotechnology, Shanghai, CN).

\section{Comet assay}

The Single Cell Gel Electrophoresis assay (also known as Comet Assay) is a sensitive technique for measuring DNA strand breaks in individual cells. This is a standard technique for evaluation of DNA biomonitoring, genotoxicity, and damage/repair $[27,36]$. The assay was performed as described by Carlos et al. [34] using the DNA Damage Detection Kit (KeyGEN BioTECH, Inc, Nanjing, China) with some modifications. Cells were exposed to cisplatin for $1 \mathrm{~h}$, washed, and incubated at $37^{\circ} \mathrm{C}$ with $5 \% \mathrm{CO}_{2}$ for 48 hours. Next, the cells were trypsinized and resuspended in $1 \mathrm{~mL}$ culture medium. After that, $10 \mu \mathrm{L}$ of cells $\left(1 \times 10^{4}\right)$ were encapsulated in $75 \mu \mathrm{L} 0.7 \%$ low-melting-point agarose at $37^{\circ} \mathrm{C}$. This mixture was layered onto slides precoated with $0.5 \%$ standard agarose and covered with a coverslip. The agarose was allowed to solidify for $10 \mathrm{~min}$ at $4^{\circ} \mathrm{C}$, and then the coverslip was gently removed. Then, the slides were immersed in a precooled lysis buffer (Cat\# KGA240) for at least $90 \mathrm{~min}$ at $4^{\circ} \mathrm{C}$ followed by incubation in an alkaline buffer $(1 \mathrm{mM}$ EDTA and $300 \mathrm{mM} \mathrm{NaOH}$; $\mathrm{pH}>13$ ) for 60 minutes at room temperature to allow for DNA unwinding and alkalilabile site expression. Electrophoresis was conducted in the same alkaline buffer for 30 minutes at $25 \mathrm{~V}(0.86$ $\mathrm{V} / \mathrm{cm}$ ) and $300 \mathrm{~mA}$. After electrophoresis, the slides were washed at least three times with $0.4 \mathrm{mM}$ Tris- $\mathrm{HCl}$ $(\mathrm{pH}=7.5)$ prior to staining with propidium iodide (PI) $(20 \mu \mathrm{L})$ (KeyGEN BioTECH, Inc, Nanjing, China) for $10 \mathrm{~min}$. Comet tails were visualized using a fluorescence microscope with a FITC filter. In these experiments, cells with high amounts of cisplatin-induced cross-links have shorter tails compared to cells in which cross-links have been repaired effectively. This is because unrepaired platinum-induced DNA cross-links remain together after DNA degradation, resulting in larger DNA fragments $[37,38]$. The tail length is proportional to the DNA repair. DNA was stained and the percentage of DNA in comet tails, tail length (in $\mu \mathrm{m}$ ), tail moment (TM), and tail olives moment (TOM) were quantified to determine the extent of DNA damage/repair (CASP 1.2.3beta2 version, Krzysztof Konca, CaspLab.com).

\section{Statistical analysis}

SPSS 17.0 (Chicago, IL, USA) was used for all quantitative analyses, except for microarray data. Data are expressed as arithmetic mean $\pm \mathrm{SD}$ of the number (n) of experiments. Samples were analyzed with repeated measures analysis of variance, and differences in incidences were analyzed using one-way ANOVA. Differences in positive area and integrated optical density (IOD) in each field of the $\times 400$ in situ hybridization photographs were determined using Image-Pro plus vision 6.0. Overall survival was defined as the time from initial cytoreductive surgery to the date of the last follow-up or death. Survival time courses were evaluated using the Kaplan-Meier method, and groups were compared using the log rank test. $p<0.05$ was considered statistically significant.

\section{ACKNOWLEDGMENTS}

The authors thank Gordon Zhuo Guo for technical support regarding computational approaches, Chun Peng for providing the cell lines, and Jiyong Jiang for acquiring and managing patients.

\section{CONFLICTS OF INTEREST}

The authors have no potential conflicts of interest to disclose. 


\section{GRANT SUPPORT}

This work was supported by grants from the National Basic Research Program of China (973 Program) (program No. 2012CB517600; grant No. 2012CB517603) and the Chinese Ministry of Science and Technology Projects (No. 2008DFA30720).

\section{REFERENCES}

1. Ye G, Fu G, Cui S, Zhao S, Bernaudo S, Bai Y, Ding Y, Zhang Y, Yang BB, Peng C. MicroRNA 376c enhances ovarian cancer cell survival by targeting activin receptorlike kinase 7: implications for chemoresistance. J Cell Sci. 2011; 124:359-68.

2. Williams TI, Toups KL, Saggese DA, Kalli KR, Cliby WA, Muddiman DC. Epithelial ovarian cancer: disease etiology, treatment, detection, and investigational gene, metabolite, and protein biomarkers. J Proteome Res. 2007; 6:2936-62.

3. Dressman HK, Berchuck A, Chan G, Zhai J, Bild A, Sayer R, Cragun J, Clarke J, Whitaker RS, Li L, Gray J, Marks J, Ginsburg GS, et al. An integrated genomic-based approach to individualized treatment of patients with advanced-stage ovarian cancer. J Clin Oncol. 2007; 25:517-25.

4. McGuire WP, Hoskins WJ, Brady MF, Kucera PR, Partridge EE, Look KY, Clarke-Pearson DL, Davidson M. Cyclophosphamide and cisplatin compared with paclitaxel and cisplatin in patients with stage III and stage IV ovarian cancer. N Engl J Med. 1996; 334:1-6.

5. Saldivar JS, Wu X, Follen M, Gershenson D. Nucleotide excision repair pathway review I: implications in ovarian cancer and platinum sensitivity. Gynecol Oncol. 2007; 107:S56-71.

6. Cannistra SA. Cancer of the ovary. N Engl J Med. 2004;351:2519-29.

7. Kim SH, Lee GW, Lee MJ, Cho YJ, Jeong YY, Kim HC, Lee JD, Hwang YS, Kim IS, Lee S, Oh SY. Clinical significance of ERCC2 haplotype-tagging single nucleotide polymorphisms in patients with unresectable non-small cell lung cancer treated with first-line platinum-based chemotherapy. Lung Cancer. 2012; 77:578-84.

8. Iván Díaz-Padillaa, Andres Povedab. DNA repair-based mechanisms of platinum resistance in epithelial ovarian cancer: from bench to bedside. Clinical Ovarian Cancer. 2010; 3:29-35.

9. Brozovic A, Damrot J, Tsaryk R, Helbig L, Nikolova T, Hartig C, Osmak M, Roos WP, Kaina B, Fritz G. Cisplatin sensitivity is related to late DNA damage processing and checkpoint control rather than to the early DNA damage response. Mutat Res. 2009; 670:32-41

10. Zhen W, Link CJ Jr, O'Connor PM, Reed E, Parker R, Howell SB, Bohr VA. Increased gene-specific repair of cisplatin interstrand cross-links in cisplatin-resistant human ovarian cancer cell lines. Mol Cell Biol. 1992; 12:3689-98.
11. Yuan T, Deng S, Chen M, Chen W, Lu W, Huang H, Xia J. Association of DNA repair gene XRCC1 and XPD polymorphisms with genetic susceptibility to gastric cancer in a Chinese population. Cancer Epidemiol. 2011; 35:170-4.

12. Giovannetti E, Erozenci A, Smit J, Danesi R, Peters GJ. Molecular mechanisms underlying the role of microRNAs (miRNAs) in anticancer drug resistance and implications for clinical practice. Crit Rev Oncol Hematol. 2012; 81:103-22.

13. Mishra PJ. The miRNA-drug resistance connection: a new era of personalized medicine using noncoding RNA begins. Pharmacogenomics. 2012; 13:1321-4.

14. Tian W, Chen J, He H, Deng Y. MicroRNAs and drug resistance of breast cancer: basic evidence and clinical applications. Clin Transl Oncol. 2013; 15:335-42.

15. Kanakkanthara A, Miller JH. MicroRNAs: Novel mediators of resistance to microtubule-targeting agents. Cancer Treat Rev. 2013; 39:161-70.

16. Bowden NA. Nucleotide excision repair: why is it not used to predict response to platinum-based chemotherapy? Cancer Lett. 2014; 346:163-71.

17. Jazaeri AA, Awtrey CS, Chandramouli GV, Chuang YE, Khan J, Sotiriou C, Aprelikova O, Yee CJ, Zorn KK, Birrer MJ, Barrett JC, Boyd J. Gene expression profiles associated with response to chemotherapy in epithelial ovarian cancers. Clin Cancer Res. 2005; 11:6300-10.

18. Yang N, Kaur S, Volinia S, Greshock J, Lassus H, Hasegawa K, Liang S, Leminen A, Deng S, Smith L, Johnstone CN, Chen XM, Liu CG, et al. MicroRNA microarray identifies Let-7i as a novel biomarker and therapeutic target in human epithelial ovarian cancer. Cancer Res. 2008; 68:10307-14.

19. Ziliak D, Gamazon ER, Lacroix B, Kyung $\operatorname{Im~H,~}$ Wen Y, Huang RS. Genetic Variation That Predicts Platinum Sensitivity Reveals the Role of miR-193b* in Chemotherapeutic Susceptibility. Mol Cancer Ther. 2012; 11:2054-61.

20. Bentink S, Haibe-Kains B, Risch T, Fan JB, Hirsch MS, Holton K, Rubio R, April C, Chen J, Wickham-Garcia E, Liu J, Culhane A, Drapkin R, et al. Angiogenic mRNA and microRNA gene expression signature predicts a novel subtype of serous ovarian cancer. PLoS One. 2012; 7:e30269.

21. Ratner ES, Keane FK, Lindner R, Tassi RA, Paranjape T, Glasgow M, Nallur S, Deng Y, Lu L, Steele L, Sand S, Muller RU, Bignotti E, et al. A KRAS variant is a biomarker of poor outcome, platinum chemotherapy resistance and a potential target for therapy in ovarian cancer. Oncogene. 2012; 31:4559-66.

22. Mezzanzanica D, Canevari S, Cecco LD, Bagnoli M. miRNA control of apoptotic programs: focus on ovarian cancer. Expert Rev Mol Diagn. 2011; 11:277-86.

23. Clarkson SG, Wood RD. Polymorphisms in the human XPD (ERCC2) gene, DNA repair capacity and cancer 
susceptibility: an appraisal. DNA Repair (Amst). 2005; 4:1068-74.

24. Yin M, Yan J, Voutsina A, Tibaldi C, Christiani DC, Heist RS, Rosell R, Booton R, Wei Q. No evidence of an association of ERCC1 and ERCC2 polymorphisms with clinical outcomes of platinum-based chemotherapies in nonsmall cell lung cancer: a meta-analysis. Lung Cancer. 2011; 72:370-7.

25. Yin J, Vogel U, Ma Y, Guo L, Wang H, Qi R. Polymorphism of the DNA repair gene ERCC2 Lys751Gln and risk of lung cancer in a northeastern Chinese population. Cancer Genet Cytogenet. 2006; 169:27-32.

26. Kartalou M, Essigmann JM. Recognition of cisplatin adducts by cellular proteins. Mutat Res. 2001; 478:1-21.

27. Gyori BM, Venkatachalam G, Thiagarajan PS, Hsu D, Clement MV. OpenComet: An automated tool for comet assay image analysis. Redox Biol. 2014; 2:457-65.

28. Passetti F, Ferreira CG, Costa FF. The impact of microRNAs and alternative splicing in pharmacogenomics. Pharmacogenomics J. 2009; 9:1-13.

29. Bansal N, Marchion DC, Bicaku E, Xiong Y, Chen N, Stickles XB, Sawah EA, Wenham RM, Apte SM, GonzalezBosquet J, Judson PL, Hakam A, Lancaster JM. BCL2 antagonist of cell death kinases, phosphatases, and ovarian cancer sensitivity to cisplatin. J Gynecol Oncol. 2012; 23:35-42.

30. Miller AB, Hoogstraten B, Staquet M, Winkler A. Reporting results of cancer treatment. Cancer. 1981; 47:207-14.

31. Rustin GJ, Nelstrop AE, Bentzen SM, Piccart MJ, Bertelsen K. Use of tumour markers in monitoring the course of ovarian cancer. Ann Oncol. 1999; 10:21-7.

32. Rustin GJ, Nelstrop AE, McClean P, Brady MF, McGuire WP, Hoskins WJ, Mitchell H, Lambert HE.
Defining response of ovarian carcinoma to initial chemotherapy according to serum CA 125. J Clin Oncol. 1996; 14:1545-51.

33. Zhao JY, Liu CQ, Zhao HN, Ding YF, Bi T, Wang B, Lin XC, Guo G, Cui SY. Synchronous detection of miRNAs, their targets and downstream proteins in transferred FFPE sections: Applications in clinical and basic research. Methods. 2012; 58:156-63.

34. Wang Y, Wang Q, Zhao Y, Gong D, Wang D, Li C, Zhao H. Protective effects of estrogen against reperfusion arrhythmias following severe myocardial ischemia in rats. Circ J. 2010; 74:634-43.

35. He-nan Z, Yan W, Miao-na J, Cai-hua Z, Shen L, Yujie J. Relation of Cardiotrophin-1 (CT-1) and cardiac transcription factor GATA4 expression in rat's cardiac myocytes hypertrophy and apoptosis. Pathol Res Pract. 2009; 205:615-25.

36. Pérez C, Díaz-García CV, Agudo-López A, del Solar V, Cabrera S, Agulló-Ortuño MT, Navarro-Ranninger C, Alemán J, López-Martín JA. Evaluation of novel transsulfonamide platinum complexes against tumor cell lines. Eur J Med Chem. 2014; 76:360-8.

37. van Huis-Tanja LH, Kweekel DM, Lu X, Franken K, Koopman M, Gelderblom H, Antonini NF, Punt CJ, Guchelaar HJ, van der Straaten T. Excision Repair CrossComplementation group 1 (ERCC1) C118T SNP does not affect cellular response to oxaliplatin. Mutat Res Fundam Mol Mech Mutagen. 2014; 759:37-44.

38. Zhao H, Liu S, Wang G, Wu X, Ding Y, Guo G, Jiang J, Cui S. Expression of miR-136 is associated with the primary cisplatin resistance of human epithelial ovarian cancer. Oncol Rep. 2015; 33:591-598. 